\title{
Neurological Complications of Coronavirus Disease (COVID-19): Encephalopathy, MRI Brain and Cerebrospinal Fluid Findings: Case 2
}

Patricio S. Espinosa ${ }^{1}$, Zufe Rizvi ${ }^{2}$, Pamraj Sharma ${ }^{2}$, Fawzi Hindi ${ }^{2}$, Asia Filatov ${ }^{2}$

1. Neurology, Marcus Neuroscience Institute, Boca Raton Regional Hospital, Boca Raton, USA 2. Neurology, Charles E. Schmidt College of Medicine, Florida Atlantic University, Boca Raton, USA

Corresponding author: Patricio S. Espinosa, ps.espinosa@gmail.com

\begin{abstract}
The neurological complications of coronavirus disease 2019 (COVID-19) are being better understood as the pandemic progresses. We report a second case of a patient who presented with COVID-19 infection and encephalopathy to our institution. In addition, we report MRI brain and cerebrospinal fluid data. COVID-19 does not seem to cross the blood-brain barrier. The exact mechanisms of encephalopathy and pathological response of COVID-19 are unknown.
\end{abstract}

Categories: Internal Medicine, Neurology, Infectious Disease Keywords: covid 19

\section{Introduction}

Coronavirus disease (COVID-19) is a pandemic with more than 1,600,000 reported cases worldwide to date $[1,2]$. The neurological complications of COVID-19 are reported as the epidemic unfolds. Neurological ailments such as confusion and altered mental status have been circulating in case reports. However, evidence regarding neurological manifestation is scarce. By now, the population is familiar with the typical hallmarks of COVID-19: fever, cough and shortness of breath. However, stranger symptoms have been making the frontlines. Our institution has muddled through a case of COVID-19 encephalopathy, where a plethora of neuroimaging and spinal tap came back normal without signs of infection and other causes such as delirium were ruled out. We present a second patient with encephalopathy and COVID infection that presented to our institution, concluding that severe acute respiratory syndrome coronavirus 2 (SARS-COV-2) does not cross the blood-brain barrier. This article adds important brain imaging and cerebrospinal fluid (CSF) data about the neurological complications of this pandemic.

Received 04/15/2020 Review began 04/20/2020 Review ended 04/26/2020 Published 05/02/2020

๑) Copyright 2020

Espinosa et al. This is an open access article distributed under the terms of the Creative Commons Attribution License CC-BY 4.0., which permits unrestricted use, distribution, and reproduction in any medium, provided the original author and source are credited.

\section{Case Presentation}

A 72-year-old male with a past medical history of hypertension, hyperlipidemia and type 2 diabetes mellitus presented to the emergency department with a chief complaint of fever and dry cough. The patient reported the symptoms occurred after he came in contact with his neighbor who was a confirmed COVID-19 case, six days prior to admission. All protective measures and precautions for suspected COVID-19 infection were taken. The patient was placed in droplet precautions and contact isolation. Both sputum and nasopharyngeal cultures were negative for Strep. Blood cultures were negative, and urine analysis was negative. Influenza A and B tests were negative. His chest $\mathrm{x}$-ray revealed multifocal consolidations concerning for multifocal pneumonia (see Figure 1). 


\section{Cureus}

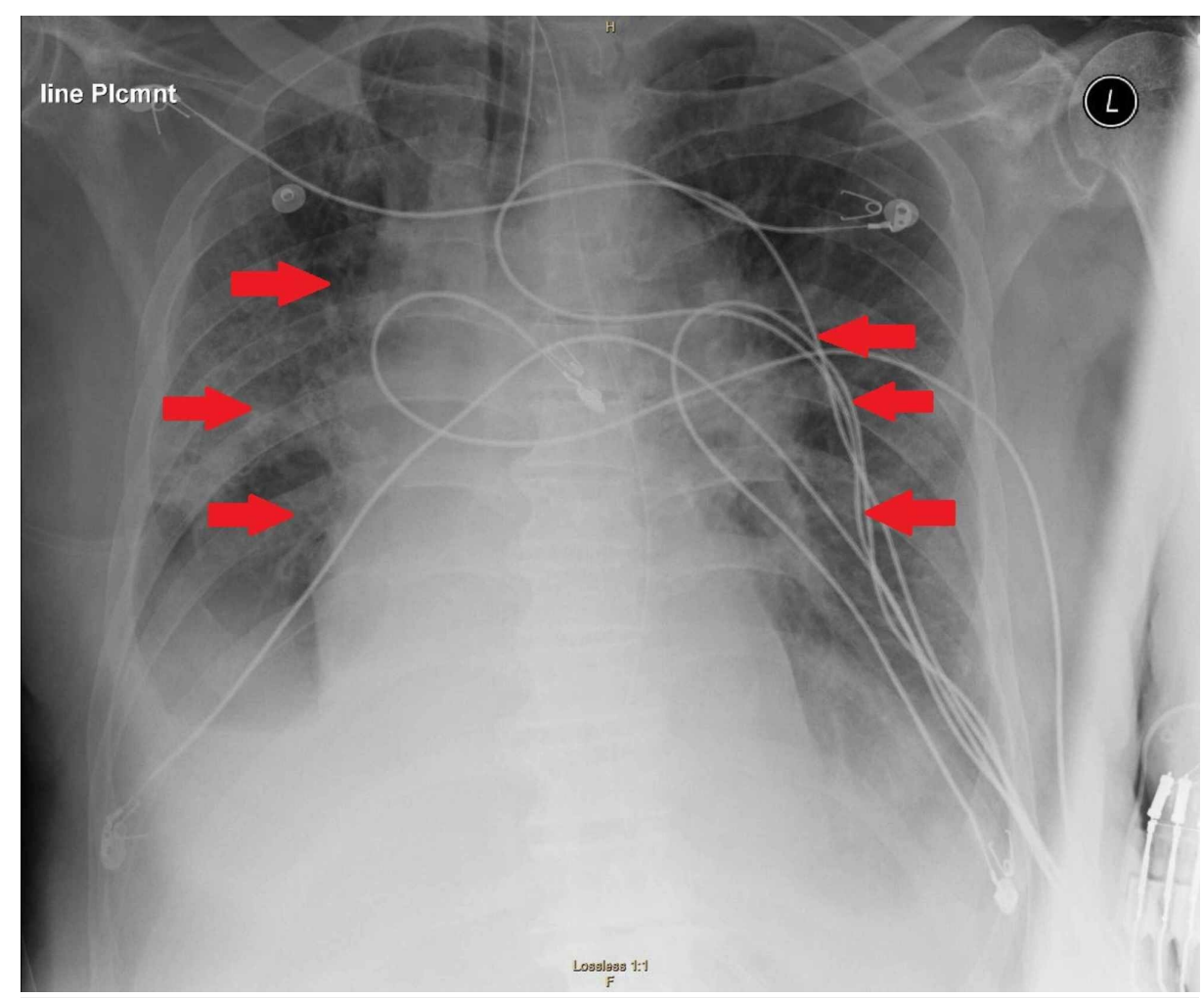

FIGURE 1: Chest x-ray demonstrating multifocal consolidations concerning for multifocal pneumonia.

The patient continued to decompensate and was ultimately intubated for acute hypoxemic respiratory failure. Hospital course was complicated by shock, requiring vasopressors. MRI brain (see Figure 2) revealed a small incidental finding of a cortical posterior left parietal infarct due to hypoperfusion in the setting of hypotension. 


\section{Cureus}
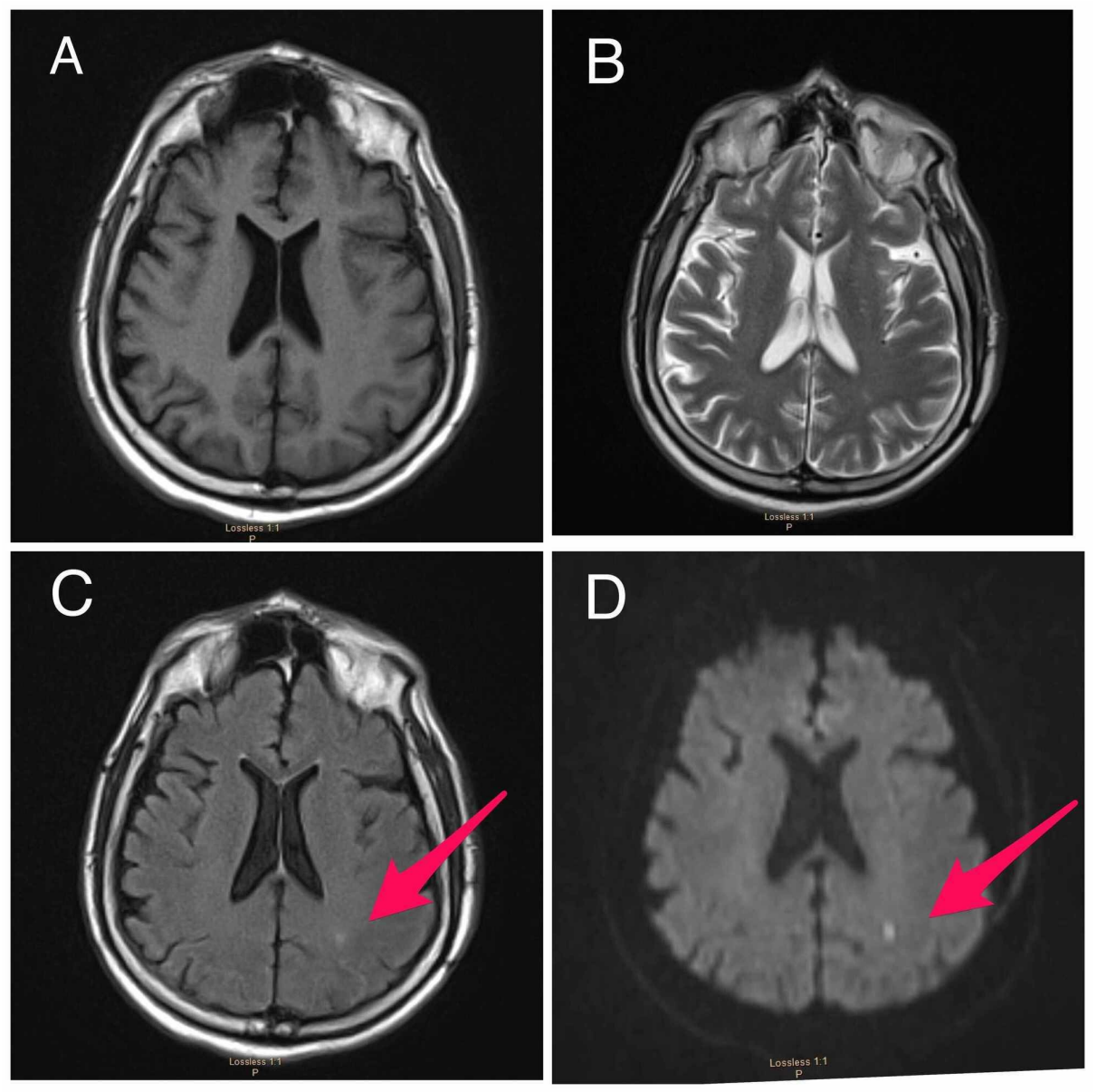

\section{FIGURE 2: MRI of the brain.}

(A) Normal T1-weighted, (B) normal T2-weighted, (C) FLAIR sequence shows increased signal in the area of the acute stroke (arrow) and (D) diffusion-weighted imaging shows an area of restricted diffusion in the left parietocoritcal region (arrow).

FLAIR, fluid attenuated inversion recovery.

SARS-CoV-2 polymerase chain reaction (PCR) testing resulted positive. Routine labs recommended by CDC for COVID-19 were obtained. Serum alanine aminotransferase level $730 \mathrm{U} / \mathrm{L}$ (normal range 10-130 U/L), aspartate aminotransferase level $735 \mathrm{U} / \mathrm{L}$ (normal range 10-34 U/L), lactate dehydrogenase 956 U/L (normal range $140-280 \mathrm{U} / \mathrm{L}$ ), C-reactive potein $10.20 \mathrm{mg} / \mathrm{L}$ (normal range $0-10 \mathrm{mg} / \mathrm{L}$ ), ferritin $6,137 \mathrm{ng} / \mathrm{mL}$ (normal range $12-300 \mathrm{ng} / \mathrm{mL}$ ), D-dimer $12.73(\mathrm{mg} / \mathrm{L}$ ) (a normal D-dimer is considered less than $0.50 \mathrm{mg} / \mathrm{L}$ ) and IL-6 $20 \mathrm{pg} / \mathrm{mL}$ (normal range $5-15 \mathrm{pg} / \mathrm{mL}$ ). The patient completed a course of ceftriaxone, azithromycin and five days with hydroxychloroquine. After being on the ventilator for 10 days, the patient oxygenation requirements gradually improved and his lung mechanics were almost normal; hence, 'sedation awakening trials' were initiated for spontaneous breathing trials, but he was persistently not arousable. The patient remained hemodynamically unstable and ventilator dependent; however, sedation was discontinued while the patient did not show any improvement neurologically. The patient did not respond to verbal command or react to noxious painful stimuli. Furthermore, only his brainstem reflexes remained intact by grimace. In order to investigate the diagnosis of encephalopathy, further diagnostics were warranted. An

electroencephalogram (EEG) (see Figure 3) was performed after the patient was off sedation for 72 hours and showed only bilateral slowing consistent with encephalopathy and no evidence epileptiform activity. 


\section{Cureus}

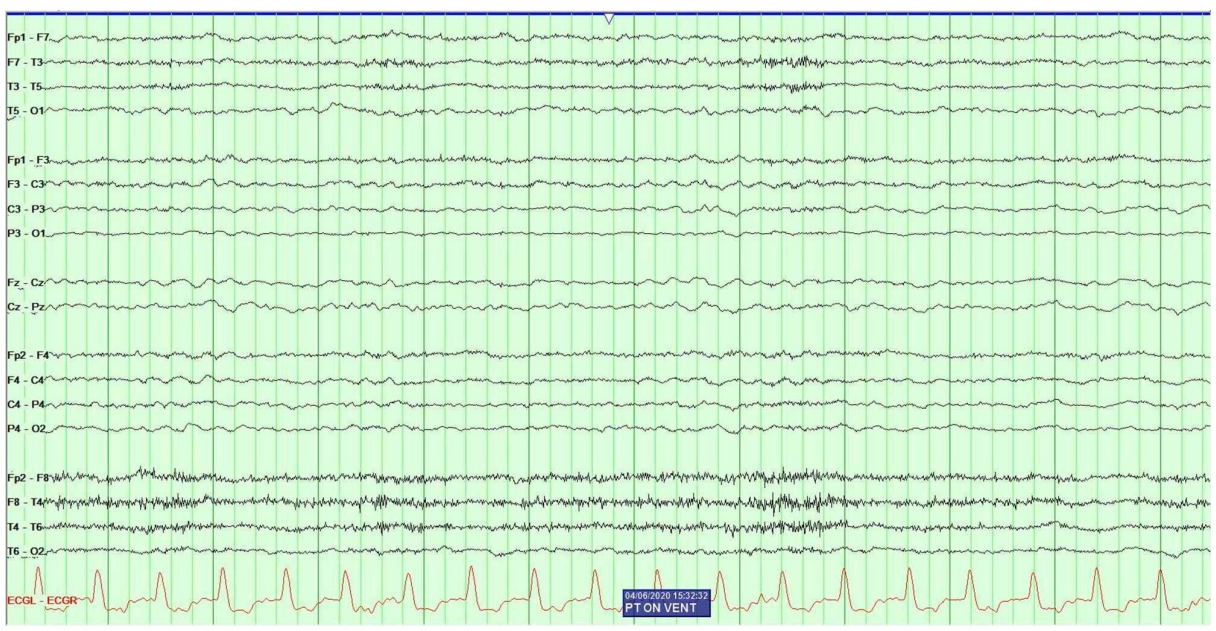

FIGURE 3: Electroencephalography revealed diffuse slowing and no evidence of epileptiform abnormalities.

Lumbar puncture was performed with CSF analysis (see Table 1). CSF analysis showed no evidence to suggest meningitis or encephalitis. Case 1, a previously published case of COVID-19 with encephalopathy, is compared with our current case which is similar in CSF findings [1].

\begin{tabular}{|l|l|l|}
\hline CSF studies & Case $\mathbf{1}$ & Case 2 \\
\hline Appearance & Clear & None \\
\hline Color & None & 2 \\
\hline WBCs & 4 & 0 \\
RBCs & 0 & 87 \\
CSF glucose & 75 & 27 \\
CSF protein & 68 & Not detected \\
HSV PCR & Not detected & Negative \\
CMV PCR & Negative & Negative \\
\hline RSV & Negative & \\
\hline
\end{tabular}

TABLE 1: CSF analysis: CSF studies show no evidence of CNS infection.

CMV, cytomegalovirus; CNS, central nervous system; CSF, cerebrospinal fluid; HSV, herpes simplex virus; PCR, polymerase chain reaction; RBC, red blood cell; RSV, respiratory syncytial virus; WBC, white blood cell.

\section{Discussion}

Patients with COVID-19 develop encephalopathy; the virus does not seem to cross the blood-brain barrier, yet this is the second case of encephalopathy associated with the SARS-CoV-2 virus in our center. CSF analysis is within normal limits. MRI of our patient with encephalopathy and COVID-19 shows no evidence consistent with structural damage to the brain. The small border zone stroke found in brain imaging is likely secondary to hypotension in this critically ill patient and is not related to the virus. MRI is a power tool in a patient with COVID-19; in this case, it assisted in the decision of continuing care versus withdrawing care. EEG is a very helpful tool in patients with encephalopathy. CSF analysis is crucial in a patient with this infection as it helps rule other causes of altered mental status.

These cases add to the body of literature that patients with this virus have encephalopathy and no signs of meningitis, encephalitis, acute inflammatory demyelinating polyradiculopathy, myositis, critical illness myopathy, Guillain-Barre syndrome or anosmia [3,4]. The cause of encephalopathy is likely multifactorial, yet the virus may contribute to the encephalopathy. Anecdotally it has been reported that the 
encephalopathy may be secondary to neurotropism through the olfactory bulb and/or hematogenous spread [5]. However, these theories have yet to be proven since CSF analysis of virus PCR cannot be done at this time, despite several attempts to contact multiple labs and institutions across the USA. In patients with COVID-19 infection and encephalopathy, medical staff should consider the possibility of nervous system infections and carry out CSF tests in time to avoid delayed diagnosis and further reduce the mortality rate of critically ill patients.

\section{Conclusions}

In our second patient with COVID-19 infection, there is no evidence of central nervous system penetration of the virus. We hypothesized that the likely cause of the encephalopathy in these patients is multifactorial. The aim of this abstract is to add to the literature information about patients with neurological complications and COVID-19, using real-time data. It is necessary to ensure that all clinicians are treating patients with the best data for the best patient outcome. As the body of literature grows, this article and others like this will help identify patterns of neurological illness amongst COVID-19 patients.

\section{Additional Information \\ Disclosures}

Human subjects: Consent was obtained by all participants in this study. Conflicts of interest: In compliance with the ICMJE uniform disclosure form, all authors declare the following: Payment/services info: All authors have declared that no financial support was received from any organization for the submitted work. Financial relationships: All authors have declared that they have no financial relationships at present or within the previous three years with any organizations that might have an interest in the submitted work. Other relationships: All authors have declared that there are no other relationships or activities that could appear to have influenced the submitted work.

\section{Acknowledgements}

We would like to thank Sameea Husain-Wilson, DO, Samer Fahmy, MD, and Aashish Neupane, MD and express our heartfelt appreciation for their significant contribution to this paper. On behalf of FAU Neurology residents and director, it was with your mere cooperation, input, enthusiasm and spirit, we could make Neurological Complications of Coronavirus Disease (COVID-19): Encephalopathy, MRI Brain and CSF Findings: Case 2 a grand success.

\section{References}

1. Filatov A, Sharma P, Hindi F, Espinosa PS: Neurological complications of coronavirus disease (COVID-19): encephalopathy. Cureus. 2020, 12:e7352. 10.7759/cureus.7352

2. Wang D, Hu B, Hu C, et al.: Clinical characteristics of 138 hospitalized patients with 2019 novel coronavirus-infected pneumonia in Wuhan, China. JAMA. 2020, 323:1061-1069. 10.1001/jama.2020.1585

3. Poyiadji N, Shahin G, Noujaim D, Stone M, Patel S, Griffith B: COVID 19-associated acute hemorrhagic necrotizing encephalopathy: CT and MRI features [Epub ahead of print]. Radiology. 2020, https://doi.org/10.1148/radiol.2020201187

4. Nath A: Neurologic complications of coronavirus infections [Epub ahead of print] . Neurology. 2020, 10.1212/WNL.0000000000009455

5. Robinson C, Busl K: Neurologic manifestations of severe respiratory viral contagions . Crit Care Explor. 2020, 2:e0107. 10.1097/CCE.0000000000000107 